\section{Exploring the Impact of Formal Internships on Biomedical Graduate and Postgraduate Careers: An Interview Study}

Deepshikha Chatterjee, ${ }^{\dagger *}$ J. Kevin Ford, ${ }^{\ddagger}$ Julie Rojewski, ${ }^{\S}$ and Stephanie W. Watts" 'Department of Psychology, Salem State University, Salem, MA 01970; 'Department of Psychology, sDepartment of Educational Administration, and "Department of Pharmacology and Toxicology, Michigan State University, East Lansing, MI 48824

\begin{abstract}
Graduate students and postdocs in science, technology, engineering, and math fields are faced with a wide range of career paths to employment, but they are often not trained to effectively pursue these opportunities. The lack of career management skills implies long tenures in graduate school for many students, especially as tenure-track positions in academia dwindle. At our university, we used a cohort model in which graduate students and postdocs were encouraged to apply to the Broadening Experiences in Scientific Training program (BEST under the aegis of the National Institutes of Health) that provided opportunities to gain career management skills, engage in career exploration, and complete at least one formal internship. In this interview study of the BEST trainees, we investigated the efficacy of internships as career exploration tools and associated outcomes. Our findings show that internships were seen as effective career exploration and self-development vehicles that influenced participants' long-term career goals. Graduate students and postdocs reported gaining transferable knowledge and skills, in addition to receiving valuable industry mentoring and networking opportunities.
\end{abstract}

\section{INTRODUCTION}

Complex and dynamic changes have been underway in both academic and industry jobs in the science, technology, engineering, and mathematics (STEM) fields (Carnevale et al., 2011). There exists a crisis wherein biomedical students either find themselves in longer tenures as graduate students or are forced to accept multiple postdoc positions before possibly finding a tenure-track position (Monastersky, 2007; Larson et al., 2014). Others who decide not to pursue an academic research career can find themselves in diverse career paths that they were not necessarily trained for or adequately prepared to enter (Myers et al., 2015). Many different explanations have been offered for this crisis; chief among them are the dwindling number of tenure-track positions, making the academic job search increasingly competitive, and the hesitance of academic programs/advisors to help prepare graduate students for alternate career paths (Austin and Wulff, 2004; Austin, 2010; Carney et al., 2006; Xue and Larson, 2015; Myers et al., 2015).

The industry job search is marked by an array of viable employment options and career tracks for STEM graduates (Carnevale et al., 2011; Council of Graduate Schools and Educational Testing Service, 2012). Capitalizing on such varied opportunities and career paths may be difficult to accomplish for individuals working hard in laboratories to obtain PhDs or complete postdocs in research-intensive institutions. Arthur and Rousseau (1996) describe the pursuit of "boundaryless careers," that is, the onus of an individual's progression in a work domain shifts from "reliance on organizational promotions and career paths" to self-initiated attempts at exploring opportunities for mobility (Briscoe et al., 2006, p. 31). This mandates higher levels of career exploration (Mirvis and Hall, 1994) and career management skills (Bridgstock, 2009). It has been
Rebecca Price, Monitoring Editor Submitted Sep 24, 2018; Revised Dec 10, 2018; Accepted Jan 29, 2019

CBE Life Sci Educ June 1, 2019 18:ar20

DOI:10.1187/cbe.18-09-0199

*Address correspondence to: Deepshikha Chatterjee (chatterjee.dia@gmail.com) (C) 2019 D. Chatterjee et al. CBE-Life Sciences Education (๑) 2019 The American Society for Cell Biology. This article is distributed by The American Society for Cell Biology under license from the author(s). It is available to the public under an Attribution-Noncommercial-Share Alike 3.0 Unported Creative Commons License (http://creativecommons.org/licenses/ by-nc-sa/3.0).

"ASCB®" and "The American Society for Cell Biology $\circledR^{\prime \prime}$ are registered trademarks of The American Society for Cell Biology. 
noted that graduate training often does little to equip students with knowledge of career options and best practices for exploring career options or to help students by enhancing career management skills (Nyquist et al., 2001).

Industry does value graduate students who have the technical competence from research laboratory experiences and who know their disciplines well, but hiring managers are also often looking for additional competencies such as time management, initiative taking, leadership skills, and communication and other skills whereby graduate students can put their knowledge and abilities to effective use outside academia (Passow, 2007; Fuhrmann et al., 2011). While STEM graduates are often well trained on the "hard" technical skills and possess highly specialized domain-specific knowledge, skills, and abilities (KSAs) that are portable across multiple types of career tracks, graduate training often underemphasizes the development of "softer" skills and career management skills (Fuhrmann et al., 2011). This is a problem, as one of the hallmarks of managing successful self-directed career exploration and career management is the development of competencies beyond technical skills (Sullivan, 1999).

Stumpf and colleagues (1983) define career exploration as a long-term, dynamic process in which an individual intentionally gathers information about possible jobs and/or career tracks. The career exploration process entails at least four different sets of activities-bounding the domains one would like to explore, seeking appropriate avenues for exploration, engaging in either systematic or fortuitous exploration, and determining the degree or amount of exploration one must conduct (Stumpf et al., 1983). Career beliefs, such as one's employment outlook, and affective reactions encountered in response to ambiguity and uncertainty generated by exploration (Bright and Pryor, 2005) are affected and impacted by the career exploration process in a reciprocal feedback loop (Stumpf et al., 1983). Career exploration attempts are catalyzed by several different triggers, such as chance events that expose an individual to a possible career track (Mitchell et al., 1999), individual differences in vocational identity, ${ }^{1}$ career mind-set, career orientation and environmental influences (Gushue et al., 2006), and key transitions that may occur in an individual's life (Blustein, 1997).

Zikic and Hall (2009) note how barriers such as lacking the confidence, skills, and/or abilities to undertake career exploration may work to curtail an individual's attempts. Graduate students and postdocs in STEM fields may also function in academic environments that afford limited opportunities to explore, as the focus is on meeting the demanding goals of the labs where they are employed as research assistants. Academic advisors may also give the impression that other career tracks are not as prestigious or status enhancing and thus "value academic jobs over industry jobs" (Golde, 2005, p. 691). In addition, students may not be "aware of this need for career exploration because their immediate environment does not encourage this attitude" (Zikic and Hall, 2009, p.19).

The Broadening Experiences in Scientific Training (BEST) program was created under the aegis of the National Institutes

${ }^{1}$ Vocational identity is defined as "an awareness of, and ability to specify one's own interests, personality characteristics, strengths, and goals as they relate to making career choices" (Leong and Morris, 1989, p. 117). of Health (NIH) and 17 universities across the United States with the goal to help biomedical students mitigate exactly such barriers and to enhance their career options and career management skills by facilitating career exploration (Alberts et al., 2014; Myers et al., 2015). At our university, a cohort model was created in which graduate students and postdocs were encouraged to apply, were selected into the program, and were then as a group provided opportunities to gain career management skills, learn about career options to facilitate career exploration, and complete one or two formal internship experiences. For example, graduate students and postdocs were given a variety of career-related workshops and mentoring and networking opportunities and were encouraged to complete more than one internship. The purpose of the present study was to investigate the efficacy of their internships as career exploration tools as well as the outcomes of this form of career exploration.

There is limited research on the efficacy of internships as a career exploration tool for STEM graduate students and postdocs. While there exists research on the efficacy of internships for undergraduate students across multiple domains (Binder et al., 2015), we were able to find only one study on the efficacy of internships for STEM graduates (Schnoes et al., 2018). In this multimethod study, the researchers focused on describing the Graduate Student Internships for Career Exploration (GSICE) program. Similar to the effort at our university, the GSICE program emphasized two key components whereby students participated in 1) a workshop designed to stimulate career exploration efforts, with course content that included activities such as self-assessment, career exploration, assessing one's fit with various career paths, and strategizing goal pursuit; and 2) an internship experience that included formalized internship programs as well as positions specifically cultivated for GSICE through relationships with local employers. Participating in internships was seen by the participants as an important experience that helped them devote some designated time for career planning, clarified career goals, and affected career paths postgraduation. Most students either described their faculty as supportive of their career exploration efforts or indicated that their advisors remained neutral.

The central focus of the Schnoes et al. (2018) study was describing the GSICE program and the development of the workshop course content, of which the internship was one component. They found that the programs that provided students with career-building skills increased their confidence in exploring career options and aided in their decision-making. The current study builds on this work by placing the internship in the foreground of students' career exploration efforts and examining in-depth issues that were of secondary importance to the Schnoes et al. (2018) study. We crafted our interviews of internship participants with four goals in mind. The first purpose was to explicitly identify the KSAs gained during the course of the internships undertaken by biomedical graduate students and postdocs. The second purpose was to assess what KSAs they were able to translate from academic work to the internships and how the internship experience and gains in KSAs were then applied in their academic work. Thus, in our study, we explored not only what has been learned, but also the extent to which the learning was generalizable across different contexts. The third purpose was to examine the mentoring and 
networking experiences obtained during internships and how these experiences influenced students' career exploration efforts and their career decisions. The fourth purpose was to explore how pursuing an internship had affected graduate students and postdocs' long-term career-related decisions. While Schnoes et al. (2018) discussed the importance of the internship experience on career direction and career confidence, we investigated more specifically how the experience helped open participants to career options (i.e., opening new doors, closing a career option, or keeping a career option open as a possible avenue).

\section{METHODS}

\section{Research Context}

This study was crafted under the overarching context of an intervention that was rolled out at our university (i.e., BEST program, created under $\mathrm{NIH}$ with 17 university partnerships). The findings described here emerge from structured interviews of 17 BEST candidates who completed at least one internship as part of their involvement in BEST at our university (i.e., these participants are not graduate students or postdocs at any of the other BEST institutions). These 17 participants represent $15 \%$ of the overall participants who had participated in the BEST program $(N=113)$. The interviews were conducted over a span of 2 years (between 2016 and 2018) following best practices recommended for qualitative research (O'Brien et al., 2014). To compensate the principal investigators for allowing their graduate students and postdocs to participate in BEST, they were awarded a one-time sum of $\$ 2000$. This research was approved by our university institutional review board (IRB \#x13-824e).

\section{Qualitative Approach and Rationale}

We used a case study approach to illuminate the key research questions. In line with recommendations on crafting case studies (Hancock and Algozzine, 2016), we had the appropriate study conditions to use a case study approach. First, we had a group of students and postdocs who had self-selected themselves into the BEST program (i.e., they were in their natural context) and had completed at least one internship during their tenure (i.e., they were bound by time and space). Second, our research questions were prime candidates for a case study approach, as we aimed to describe how internships affect career decisions. Given our research questions, we used an interpretivist paradigm (Thanh and Thanh, 2015).

\section{Participants}

Our sample consisted of 15 biomedical graduate students and two biomedical postdocs for a total sample of 17 participants (70.58\% female, $N=12$ ). Participants represented a wide cross-section of doctoral programs such as pharmacology and toxicology, cellular and molecular biology, plant biology, chemistry, and genetics. Participants in the internships were typically in their third or fourth years in their $\mathrm{PhD}$ programs and had completed their qualifying exams. Of the 17 participants, nine had completed two internships (52.94\%). As part of the BEST protocol, the participants were initially encouraged to take on two internships that were related to their biomedical backgrounds. However, as the BEST program progressed, some students found it more difficult to do two internships while also balancing their bench research, while others decided that just doing one internship was enough to gauge their career interests and fit. All participants remained as research assistants or graduate assistants during their participation (except for one person who completed an out-of-state summer internship). Payment for internships varied-some were given fellowships, while others were paid hourly (within the hourly limits imposed on research assistants or graduate assistants by the university). Other internship opportunities were unpaid.

\section{Sampling Strategy}

The interviews were conducted by D.C. and J.K.F. in our capacity as evaluators for the BEST project (2016-2018). All BEST students were informed about the various internship opportunities via email blasts. They chose the internships depending on their individual career goals. They also self-directed their internship search by networking with the invited speakers and connecting with various employers both external and internal to the campus. Of these, we contacted 17 graduate students and postdocs at our university who had completed at least one internship to participate in an interview, and they all agreed to participate in the current research study. Given our sample was a highly homogenous one (i.e., only biomed graduate students and postdocs were recruited) and our research questions were highly specific to an issue faced in that population, we had anticipated that sampling saturation would be achieved fairly early in our set of interviews (Mason, 2010). Guest et al. (2006) conducted a study to establish how many interviews must be conducted before sample saturation occurs and found that, in samples with a high degree of homogeneity, sampling saturation can be achieved with as little as six interviews. In our case, the first six interviews still showcased differences, but by the 12th interview, we found that similar themes began surfacing. At this point, a decision was made to capture an additional five interviews, and if similar themes were observed again, then we would stop conducting more interviews. On the basis of this rationale and the recommendations offered in the literature on qualitative methods (Guest et al., 2006; Mason, 2010), we stopped conducting new interviews after the 17th interview.

\section{PROCEDURE}

\section{Researcher Characteristics}

The primary researchers for this study were one doctoral-level graduate student and one doctoral-level organizational psychologist. Both of us served as interviewers and coded all data. In line with the best practices in reporting qualitative research findings, we would like to acknowledge the role that our training as organizational psychologists is likely to have played in how this research was executed (O'Brien et al., 2014). Given our backgrounds, we drew upon two primary literatures in organizing our thinking: 1) careers and 2) training. On the basis of research in careers, we know that employers prefer individuals who have engaged in some career exploration (Sullivan and Baruch, 2009), and we assumed that internships would lead students to think more broadly about their careers. We wanted to put this idea to the test and were interested in explicating how internships affect students' career conceptions and their career exploration attempts. In addition, we focused on assessing how graduate students and postdocs transferred their learning from the internships to their labs, and whether or not they were able to transfer their training received in the academic world to their 
internship sites. This idea of learning "transfer" is borrowed from the training literature (Baldwin and Ford, 1988; Ford et al., 2018). Overall, our academic training acted as a lens to understand how internships may facilitate building students' competencies and soft skills that may be considered attractive to potential employers. Both of us were committed to accepting the stories that unfolded with the data and made conscious attempts to not push any personal agenda onto the categorization of story content.

\section{Ethical Issues Pertaining to Human Subjects}

All interviews were conducted as part of the BEST program at our university with approval from our institutional review board. The interviews were conducted over the phone. Participants were informed that the interview was 45-50 minutes long at the outset, and a consent statement was read out to them. Once participants had noted their agreement to participate in the research and had given us due permission to audio-record their interviews, we dove into the interview protocol. One individual out of the 17 participants did not agree to a recording of the interview but gave us permission to transcribe the interview in real-time instead. This request was honored.

Participants were also informed that all data would be de-identified and at no point would we share reports with disaggregated data wherein they could be identified. In addition, participants were offered opportunities to ask questions about the research study itself both at the beginning and at the end of the interview protocol. Voice recordings were saved in a locked filing cabinet and then destroyed after the interviews were transcribed, and all data files were saved on a password-protected server.

\section{Data-Collection Methods and Data Processing}

We transcribed the interviews, and codebooks were drafted based on these transcribed interviews. The timeline for the interviews was decided based on 1) when the students completed their internships, 2) when students' completion data were made available to us, and 3) when the interviews could be scheduled. As such, some interviews were conducted within a few weeks after internship completion, while others were conducted a few months after internship completion. The internships were a foundational experience for participants, and they had no difficulty in answering the structured questions despite the length of time that had passed between completion of the internship and the interview. Our data-collection instruments and the interview guide and protocol remained constant throughout the study.

\section{Interview Guide and Protocol}

The interview guide was crafted based on key research questions and the interview protocol followed a structured interview format (see Appendix A in the Supplemental Material). Participants were interviewed by the same two researchers. The structured interview format ensured that all participants were provided the same opportunities to reflect on the key research questions relating to their career exploration. Follow-up questions were asked as necessary, although for consistent application of the interview protocol, follow-up questions were minimized. The interview questions were divided into four critical parts: 1) descriptions of the internship context, 2) assessing the internship outcomes, 3) exploring whether or not key
KSAs were transferred as participants moved between the industry and lab contexts, and 4) examining the influence of internship on career goals. Before being implemented in an interview context, both the interview guide and the interview protocol were shared with the broader BEST team at our university. Feedback from the team of biomedical faculty was taken into consideration to ensure that the vocabulary used during the interviews translated well to the biomedical context so that we could minimize potential for errors based on linguistic differences that are often inherent in different fields of study.

\section{Data Analysis}

We started the qualitative data analysis by surfacing themes and concepts (Hill et al., 1997; Ritchie et al., 2013) and chose to do this process manually. Our focus was to generate descriptive accounts from our data. Both the lead authors independently reviewed the transcripts of each interview and then coded and classified data into initial categories based on the interview questions. For example, we included as categories "KSAs gained," "academic to applied transfer of KSAs," "applied to academic transfer of KSAs," "faculty mentor support perceptions," "mentoring opportunities," "networking opportunities," "influence of internship on long-term career plans," and "self-insights." Next, both the coders independently classified all the content in the transcripts into these categories. In face-to-face meetings, the categorized raw data were compared. Where we disagreed with any categorization, we obtained consensus by reviewing the transcripts and discussing the relevant instance(s) and issue(s). This process helped us construct an overall conceptual framework in which to present the data obtained from the interviews.

Next, the lead authors sorted and synthesized across the various codes generated from the data to surface key themes and classifications. Note, in line with best practice recommendations, we did not index our data, because our structured interview format had already guided the participants to respond to a "very precise structure within the topic guide" (Ritchie et al., 2003, p. 225). To sort the data, we collapsed the many different subthemes obtained in step 1 into broad categories that fit our data. Because classification occurs at a higher level of abstraction, and it is easy to stray away from the meaning inherent in the data (Ritchie et al., 2003), every attempt was made at this point in the data analytic strategy to stay close to the language used by the participants. We did not yet imbue the data set with any terms from the research literature, and we also ensured that the subthemes that did not neatly cluster into a category were not dismissed or abandoned as irrelevant. Finally, the codes and the themes so generated were assessed and refined using terms from the literature to create a categorization scheme. In this way, we were able to craft core ideas that were representative of, and succinctly described, the raw data in the transcripts. For example, when coding for KSAs, we put this approach into action as follows: In total, 123 KSAs were coded across the interviews. After common codes were accounted for, 67 unique subthemes emerged. Where we saw connections between the various subthemes, we combined them into a broad theme. For example, "business knowledge" and "business terms" were collapsed into "business knowledge," and "functioning on diverse teams" and "functioning on diverse stakeholder teams" were collapsed into "teamwork skills." This process yielded 48 broader subthemes. At the next level of distillation, we identified the 
different subthemes that clustered together, and this process yielded 10 key KSA themes. A similar process was repeated for all other study variables of interest. These subthemes and themes are presented in the sections that follow.

Thus, in the current case study, we followed a stage model of analysis (Hancock and Algozzine, 2016). We completed the following stages: 1) identified a priori research questions, 2) determined analytic categories to be explored, 3) read through the transcripts and established grounded categories, 4) sorted the data into the various categories, 5) counted the frequencies of each category representation to showcase the magnitude of the theme to the discussion at hand, and 6) evaluated the data and patterns observed in light of what we know from the existing body of research.

\section{RESULTS}

The overall categories and subcategories that emerged from the data on the key descriptors of interest are described after a discussion of the context of the internships.

\section{Internship Context}

The internship contexts varied for the participants and included firms at the intersection of patent law and technology, scientific translation, education and advisory firms, and technology and/ or biotech firms. The duration of the internships also varied depending on different contexts-some internships spanned a time horizon of up to 9 months, while the typical time span was a semester-long experience. Across these diverse contexts, participants described responsibilities as wide ranging as writing scientific blogs, conducting market research and/or filing patents for new innovations and technologies, writing grants for not-for-profit industries to fund research, reviewing grants to evaluate scholastic and/or applied merit, meeting and shadowing industry experts, coaching effective writing and scientific reporting skills, community engagement efforts such as taking science to faith-based groups, and engaging in applied scientific research for large national labs. Generally, despite these differences, there were no discernible patterns in terms of how the different internship contexts were related to the acquisition of various KSAs, or to the type of internship outcomes obtained, or even to participants' career exploration attempts. In one case, however, a participant's internship was cut short due to data confidentiality issues. S/he stated that the internship ended up being unhelpful. For the bulk of the cases in our study, it seemed that internships of all types and all durations opened the participants' eyes to a larger world beyond their laboratories and offered them knowledge and skills that were helpful marketing tools in employment search contexts. In cases in which participants interviewed with prospective employers, they also stated that their internship experiences were positively received.

\section{Internship Outcomes}

For the internship outcomes, we examined three key indicators that were seen as valuable to students' development and career exploration: 1) knowledge and skills gained, 2) mentoring opportunities, and 3) networking opportunities.

Knowledge and Skills Gained. On the basis of the data analytic approach described earlier, we found 48 broader subthemes and identified 10 key KSA themes (see Table 1).

TABLE 1. Key themes and subthemes on KSAs identified from the interviews

\begin{tabular}{|c|c|c|c|}
\hline Theme number & Key KSA themes & Examples of subthemes of KSAs & Subthemes $(N)^{\text {a }}$ \\
\hline 1 & $\begin{array}{l}\text { Acquiring declarative knowledge } \\
\text { about the business world }\end{array}$ & $\begin{array}{l}\text { Business knowledge; scientific domain knowledge; patent } \\
\text { knowledge; regulatory work; learning about finances }\end{array}$ & 10 \\
\hline 2 & Soft skills & $\begin{array}{l}\text { Ability to handle high-pressure contexts; conflict-resolution } \\
\text { skills; time management; ability to anticipate audience } \\
\text { needs; scheduling meetings; interviewing skills; ability to } \\
\text { adapt; selling ideas; being assertive; stakeholder engagement } \\
\text { skills; quick information gathering; project management }\end{array}$ & 16 \\
\hline 3 & Communication skills & Communication skills; presentation skills; public speaking & 5 \\
\hline 4 & Teamwork skills & $\begin{array}{l}\text { Functioning on diverse teams; expectation setting in teams; } \\
\text { establishing clear roles in teams; learning about teamwork }\end{array}$ & 5 \\
\hline 5 & Scientific skills & $\begin{array}{l}\text { Developing better research ideas; ability to critique one's own } \\
\text { science; mapping concepts from one field to another; } \\
\text { translating science; reviewing grants }\end{array}$ & 7 \\
\hline 6 & Writing skills & $\begin{array}{l}\text { Technical writing; legal writing; report writing; writing business } \\
\text { plans; blog writing }\end{array}$ & 6 \\
\hline 7 & Technical skills & $\begin{array}{l}\text { Market research skills; programming skills; financial analysis; } \\
\text { new statistical techniques; prototyping skills; quality-control } \\
\text { skills }\end{array}$ & 7 \\
\hline 8 & Metacognitive skills & $\begin{array}{l}\text { New thinking skills; thinking like a businessperson; thinking } \\
\text { outside the box; using active-learning strategies }\end{array}$ & 4 \\
\hline 9 & Understanding a career path & $\begin{array}{l}\text { Understanding what it means to be a consultant; understanding } \\
\text { how the culture of an organization matters; understanding } \\
\text { organizational structures }\end{array}$ & 3 \\
\hline 10 & $\begin{array}{l}\text { Knowledge of business as a } \\
\text { process }\end{array}$ & $\begin{array}{l}\text { Understanding different business functions; understanding } \\
\text { business ethics; how different business functions intersect } \\
\text { and interrelate }\end{array}$ & 4 \\
\hline
\end{tabular}

${ }^{\mathrm{a}} N=$ number of comments that align with the key KSA theme that we generated. 
Participants believed that they gained both declarative knowledge and hard skills. Some examples of declarative knowledge gains included knowledge of the business policies, knowledge of patent law, and knowledge of the interface of finance and patent law. Participants also mentioned that they acquired technical skills such as learning new statistical techniques, how to work with new genomic data sets and tools, and how to conduct a thorough market analysis.

In addition, participants described learning a host of soft skills over the course of their internships. For example, participants described how their time management skills were put to the test as they managed both their lab work and the demands of the internship. Closely tied to this, they described navigating their internships by building their teamwork skills and learning how to work with diverse stakeholders. They often reported incidents in which improving skills like conflict resolution and expectation setting were important to facilitate work. Others described their own biases when working in multidisciplinary teams. For example, one participant shared the following self-insight with us:

I can be very dismissive of other peoples' disciplines-I don't have a very respectful view of MBAs. That's how I started. But I gained much more respect for those students and their knowledge base later on. This was very good for me to see that my impression was totally off ...There's a reason there's [sic] advanced degrees in different fields-so everyone has a different skill set to bring to the table in a multidisciplinary team.

Participants also cited their enhanced ability to anticipate audience needs and create work products such as presentations that were more audience centered. For example, one participant noted the following self-insight about managing the tension between the industry audience expectations and maintaining the quality and rigor of his/her research output:

Some of the biggest take-aways were about communication and understanding how to navigate between what the client wants and what the ultimate expectation really is and finding ways to communicate with the client to keep that goal in mind and doing the best science while you are trying to get there. They did point out that you will encounter stubborn people, so keeping in mind [sic] that it will not always be smooth sailing.
By virtue of their involvement with a nonscientific audience, a number of participants commented about their enhanced metacognitive thinking abilities, whereby they were able to see the world around them in much broader ways than before. For example, participants described learning how to step into the shoes of business stakeholders and thinking like a business-savvy person in evaluating research and/or innovations that rely on science. One participant described this theme as follows:

I worked with business folks and science folks-being able to learn that not everyone cares about the technical science, but more about business-those are the things that matter to the rest of the world. At the end of the day if you cannot market your invention in a business way, then that's not that important-it was eye opening to get out of the ivory tower approach and getting the reality check of the business settings.

Participants also described how they learned about different business functions. They showcased an appreciation for how complex the business world can be, and an understanding of how often business processes and functions work in tandem. For example, one participant described learning about "how finances work [specifically] in invention and IP [Intellectual Property] settings," while another described learning about the "different channels where one could look for business funding." Finally, participants also described how working in the industry improved their scientific skills. It was noted that the industry experience had helped them become better consumers and producers of science, specifically when it came to establishing their own internal standards of "how to stay true to science," no matter what the external conditions may push them to do, and "how to translate science for [a] lay audience."

Mentoring Received. Thirty-seven different incidents of mentoring were described. Of those, we identified 21 subthemes and distilled them down into eight key themes (see Table 2). While there was strong agreement across the board that internships provided avenues for participants to gain mentoring and advice from industry representatives, the frequency and the quality of mentoring differed. Six participants (35.29\%) stated that they received a high degree of mentoring, and seven participants $(41.17 \%)$ stated that they received high-quality mentoring in which their supervisors and/or business colleagues took personal interest in shaping and molding their career trajectories.

TABLE 2. Key themes and subthemes on mentoring identified from the interviews

\begin{tabular}{|c|c|c|c|}
\hline Theme number & Key mentoring themes & Examples of subthemes of mentoring & Subthemes $(N)^{\mathrm{a}}$ \\
\hline 1 & Degree of mentoring & No mentoring; high degree of contact; variable degree of contact & 5 \\
\hline 2 & Quality of mentoring & $\begin{array}{l}\text { Very helpful; received mentoring from senior/famous people; provided } \\
\text { encouragement; high quality of feedback; instrumental in next career } \\
\text { move }\end{array}$ & 7 \\
\hline 3 & Observational learning & Mentor's career path presented as an example & 2 \\
\hline 4 & Career guidance & $\begin{array}{l}\text { Presented alternate career paths; advice on variety of issues, such as what } \\
\text { industries to target }\end{array}$ & 3 \\
\hline 5 & Advice on deliverables & Thesis advice; advice on presentation and writing skills & 2 \\
\hline 7 & Shared own network & Networking with mentor's collaborators & 1 \\
\hline 8 & $\begin{array}{l}\text { Emergent mentors via } \\
\text { network effects }\end{array}$ & $\begin{array}{l}\text { As a result of networking, new mentoring relationships emerged (over } \\
\text { email) }\end{array}$ & 1 \\
\hline
\end{tabular}

${ }^{\mathrm{a}} N=$ number of comments that align with each of the subthemes that we generated. 
TABLE 3. Key themes and subthemes on networking identified from the interviews

\begin{tabular}{llll}
\hline Theme number & \multicolumn{1}{c}{ Key networking themes } & \multicolumn{1}{c}{ Examples of subthemes of networking } \\
\hline 1 & Degree of networking & $\begin{array}{c}\text { No networking; high degree of contact; variable connectivity with } \\
\text { network }\end{array}$ \\
2 & Quality of networking & Met diverse people; good collaboration opportunities & 5 \\
3 & Type of networking & Networking for career change; networking for career advice & 2 \\
4 & Use of networking opportunities & Networking opportunities not used at all; networking opportunities & \\
& & not used since the internship & 2 \\
5 & Attitude toward networking & Realized the importance of networking in applied work & 1 \\
\hline
\end{tabular}

${ }^{a} N=$ number of comments that align with each of the subthemes that we generated.

TABLE 4. Key themes and subthemes on academic to industry learning transfer

\begin{tabular}{|c|c|c|c|}
\hline Theme number & $\begin{array}{l}\text { Key academic to industry learning } \\
\text { transfer themes }\end{array}$ & Examples of subthemes of learning transfer & Subthemes $(N)^{\text {a }}$ \\
\hline 1 & Scientific knowledge & $\begin{array}{l}\text { Scientific knowledge; stay true to science; knowledge from classes; } \\
\text { expertise on one's research topic }\end{array}$ & 5 \\
\hline 2 & Specific research skills & $\begin{array}{l}\text { Writing skills; critical reading skills; interpersonal skills; presenting } \\
\text { skills; technical skills }\end{array}$ & 7 \\
\hline 3 & Personality attributes & Detail-oriented & 1 \\
\hline
\end{tabular}

${ }^{a} N=$ number of comments that align with each of the subthemes that we generated.

For example, one participant shared the following: "[The] director was very helpful and open in making it a good experience; [s/he was] instrumental in doing a postdoc to get a level of experience needed for nonprofit work and the push to do outreach efforts." Another participant stated the following: "[I received] general advice and [participated in] career conversations around how person got to where they are today and why person [sic] went applied; ongoing conversations since the internship that could lead to a job." Another participant described the differences between academic mentors' and industry mentors' styles of mentoring, stating that "[It was a] very different experience in this setting" because "the end goal is different, no publish or perish pressure."

Two participants $(11.76 \%)$ in our sample stated that the mentoring quality was variable or that there was only some degree of contact. One participant recalled that his/her mentor "talked about alternative career paths" and that s/he "appreciated the honesty in conversations." Finally, two participants $(11.76 \%)$ reported not receiving any mentoring at their internship sites.

Networking Opportunities. In total, we found 32 different networking codes and 12 unique subthemes that we distilled into five broader subthemes. Here, we did not distill the data any further (see Table 3). While there was a strong consensus among participants that they had opportunities to build their networks at their internships, there was variation in the type and quality of networking opportunities offered at the internship sites. For the most part, participants (88.23\%) described networking with both internal and external teams at the internship sites and/or different industry partners. For example, one participant described how the internship "has been very very [sic] helpful, know many more $\mathrm{PhDs}$ far outside the $\mathrm{XX}^{2}$

\footnotetext{
${ }^{2}$ Please note $X X$ is used to redact any information that could potentially identify a participant.
}

department" and how s/he got to work with people from different offices connected to the internship site. Another participant said that networking during the internship helped move "[me from the] introverted box and forcing me to talk to a ton of people." An insight gained by another participant from this opportunity was to "never pass up an opportunity to meet with someone because it could be valuable."

Participants also acted on the networking opportunities offered to proactively curate the relationships that could yield avenues for future employment. In some cases, participants also reached out to their networks for career advice. For example, a participant described using social media as a follow-up to the networking received at his/her internship site:

One guy on XX meeting has followed me on Instagram-and he and I are talking about experimental stuff [sic]; we have connected with 75 people (on Facebook and in person) who are living with XX disease. So I have these contacts now. I am an admin on these support groups. This internship forced me to get out there-and I am thinking about what more I can do than I am already doing - it is easy to be stuck in a lab and forget the details. I intend to use the blog to communicate with the patients, and to learn from the patients, to use these contacts for both research and social work perspective.

\section{Transferring Learning between the Academic and the Industry Worlds}

Another goal of this case study was to explore the extent to which participants were able to transfer what they had learned in the academic contexts to their internship sites, and vice versa (see Tables 4 and 5 for key themes).

Transfer from Academic to Industry Context. In total, for transfer of learning from academic to industry context, 43 codes emerged across the interviews, and we extracted 20 unique subthemes that were then condensed to three key 
TABLE 5. Key themes and subthemes on industry to academic learning transfer

\begin{tabular}{lll}
\hline Theme number & $\begin{array}{c}\text { Key industry to academic learning } \\
\text { transfer themes }\end{array}$ & \multicolumn{1}{c}{ Examples of subthemes of learning transfer } \\
\hline 1 & Improved skills & $\begin{array}{c}\text { Better presentation skills; writing skills; time management; } \\
\text { project management } \\
\text { Learning how to reframe problems; learning how to start with } \\
\text { the goal in mind; learning how to use analogies to explain } \\
\text { concepts; more critical of reading science and looking for } \\
\text { "agendas" }\end{array}$ \\
Enhanced metacognitive thinking & More approach-oriented; broadened vision; broadened interests \\
\hline
\end{tabular}

${ }^{\mathrm{a}} \mathrm{N}=$ number of comments that align with each of the subthemes that we generated.

themes (see Table 4). Of the participants, $88.23 \%$ indicated that they were able to transfer their core research skills, such as reviewing the literature (e.g., parsing through dense material and extracting relevant information and ideas; creating and running experiments, and acting as content experts where needed). For example, one participant indicated how s/he "suggested experiments and provided intellectual value" within the internship context, and another described how his/her academic background was useful in "deconstructing science to help the applied work." Simply "knowing what's important and what's not"- that is, understanding a content domain-helped another participant process information quickly and efficiently in a fast-paced business environment. In addition, participants also mentioned their scientific writing skills as a transferable skill for the industry context.

Transfer from Industry to Academic Context. For transfer of learning from industry to academic context, 44 codes emerged across the interviews, and we interpreted 12 subthemes and extracted three key themes (see Table 5). All but three participants $(82.35 \%)$ indicated that they were able to transfer their industry learning to the academic/research lab context in a variety of ways. First, participants indicated that they were able to transfer a variety of skills. For example, they described using their presentation skills (e.g., considering the audience needs more explicitly; making the presentations more visually appealing; creating presentations that get to the point quickly) in their labs and/or research contexts. One participant indicated that s/ he now has a "better idea on creating visual presentations; presentations are now more concise and interesting for my audience." In addition, participants also indicated how they were better writers after their internship experiences. For example, one participant stated how "writing has become simpler; especially the intro [sic] and discussion are not as obnoxious and dense."
Second, participants described how the internship was instrumental in helping improve their metacognitive thinking. For example, one participant indicated how s/he is now able to "step back from the details and focus on the big picture" when presenting to an audience. Another participant described "coming up with analogies to help colleagues who might not know about a literature," while yet another explained how s/he learned the value of reframing problems clearly.

Third, participants described how they had broadened themselves at the internships. For example, participants mentioned being "more interested in machine learning now" and "more interdisciplinary." As another example, one participant stated that the internship made "me more purposeful about reading more broadly" and "taught me to rely on secondary sources of learning - network and ask others_-instead of always figuring it out for myself." As an example of broadened vision, one participant described being "better at articulating the big picture." Participants also enhanced their confidence and became more approach oriented. For example, one participant indicated that $\mathrm{s}$ /he was now "more confident in reaching out to professors for advice," while another indicated that s/he was "more open to collaboration opportunities now."

\section{Internships as Career Exploration Vehicles}

For understanding internships as vehicles of career exploration, we examined two indicators: 1) faculty mentor support and 2) the internship's influence on long-term career goals.

Faculty Mentor Support. In total, 35 coded categories emerged across the interviews for faculty mentor support, which were then combined into 20 unique subthemes before four key themes were extracted (see Table 6). Faculty mentor support was deemed a critical factor for participants to even attempt time away from the desk for an internship. One participant stated that his/her faculty mentor was "extraordinarily on

TABLE 6. Key themes and subthemes on faculty mentoring

\begin{tabular}{|c|c|c|c|}
\hline Theme number & Key faculty mentoring themes & Examples of subthemes of faculty mentoring & Subthemes $(N)^{\mathrm{a}}$ \\
\hline 1 & Supportive & $\begin{array}{l}\text { Supportive; inquires about BEST; interested in my career growth; got } \\
\text { me internship contact }\end{array}$ & 10 \\
\hline 2 & Conditionally supportive & $\begin{array}{l}\text { Conditionally supportive; supportive as long as work gets done; one } \\
\text { faculty mentor is supportive, the other not }\end{array}$ & 3 \\
\hline 3 & Non-supportive & $\begin{array}{l}\text { Presented alternate career paths; unhappy about desire to go industry } \\
\text { route; tense relationship; does not inquire about BEST }\end{array}$ & 5 \\
\hline 4 & Unknown & Unclear how faculty mentor feels & 1 \\
\hline
\end{tabular}

${ }^{a} N=$ number of comments that align with each of the subthemes that we generated. 
board" with the idea of an internship to explore industry careers. Another described the support as follows:

[My faculty mentor] has been incredibly supportive with the caveat that my research gets done first. [He] encourages me to look into other programs, will write recommendation letters for me-if a student is not going to follow the standard of being a PI, then he is very interested in helping them.

Other faculty PIs were more neutral about the internship experiences for their students. As noted by one interviewee, "As long as my work is getting done s/he is not too concerned about me putting in extra hours outside," or as stated by another, "Happy that I was finished with the internship." The pressure to complete lab work while at the same time completing an internship was well stated by one participant: "Grad school would be a lot less stressful had it not been for these internships-but at the same time there is no other good alternative."

Internships' Influence on Long-Term Career Goals. In total, 44 coded categories emerged across the interviews for internships' influence on long-term career goals, which were then condensed into three key themes: "opening a door," "closing a door," and "keeping the door ajar" (see Table 7). Across the board, participants expressed that an internship was a useful career exploration device. The percentage of participants endorsing the different themes is tabulated in Table 7. Note that even though we describe these themes individually and offer representative examples, $82.35 \%$ of the participants in our sample endorsed multiple themes when discussing the internships as career exploration tools. That is, they found that the internships gave them opportunities to open new doors, close a few doors that they had considered as relevant before the internship, and keep a few doors ajar for possible exploration in the future. One participant described how s/he engaged in such career exploration and how s/he was able to override the stigma associated with wanting to go the industry route:

Overall BEST has been a very great experience-it has introduced me to careers that were new, and careers that I thought would be great, but then I found out otherwise! So it has been very helpful in helping cross things off the list-things that I would or would not do. It made me feel like it's not a bad thing that it's okay to not want to be a PI! There is a lot of stigma around not going the route of PI: the climate in my department is definitely for going the PI route; the non-PI stuff is what crappy [sic] graduate students do!
First, participants $(20.45 \%)$ viewed the internships as an exercise in "closing doors"- that is, they described how the internships had given them a chance to understand what working in a particular context looked like and how their experiences had informed their decisions that a particular applied experience was not something they would care to do long term. For example,

[I] did the internship because I was thinking more seriously about pursuing science from a more commercial perspective. It is daunting to know how much work goes into science entrepreneurship, so I do know that I wouldn't want to be an entrepreneur. It did give me a great window in the world of working for private industry

Similarly, another participant stated that his/her internship confirmed that s/he does "not want to be in academic research."

Second, participants (25\%) also viewed the internships as an exercise in "keeping the door ajar"-that is, they described how the internships had given them a chance to explore one context, and how they were now more open to exploring what else was out there before making a firm decision on their career directions. For example, a participant shared that s/he "would like to work as a research scientist-where I could do thatthat's an open question for now." Another participant described future career exploration efforts as follows:

I don't have a clear path on what I want to do-but I have thought about entrepreneurship and working with smaller companies-this is stuff that MBAs know, but XX folks don't know. And if I go to smaller venture companies, then I can showcase this [internship] experience. I am trying to get a feel for what I enjoy. I enjoy teaching a lot, my reviews are strong, and I had fun; I don't want to close off the entrepreneurial route though-I haven't hated this either!

However, the bulk of the participants (54.54\%) viewed the internships as an exercise in "opening doors"-that is, they described how the internships had given them the opportunity to see a world of possible employment settings that would have remained hidden from them had they simply stayed in their labs and not ventured out. For example, one participant shared that the internship "opened my eyes about what a researcher could do for an invention disclosure/patent" and how the person saw this as a "long-term career" path. Similarly, another participant indicated that $\mathrm{s} /$ he "found a new career path-law school [is now] a serious option." Another participant described how the internship has influenced long-term career goals:

TABLE 7. Key themes on internship's influence on long-term career plans

\begin{tabular}{|c|c|c|c|}
\hline Theme number & Key internship influence themes & Examples of key internship influence & $\%(N / 44$ instances $)$ \\
\hline 1 & Closing a door & $\begin{array}{l}\text { Do not want to do R1 kind of work; do not want to do applied } \\
\text { work }\end{array}$ & $20.45(N=9)$ \\
\hline 2 & Keeping a door ajar & $\begin{array}{l}\text { Do not want faculty position, unless it is a smaller liberal arts } \\
\text { college/institute; perhaps will pursue science policy }\end{array}$ & $25(N=11)$ \\
\hline 3 & Opening a door & $\begin{array}{l}\text { Open to pursuing the nonprofit world; interested in patent } \\
\text { law; interested in applied work. }\end{array}$ & $54.54(N=24)$ \\
\hline
\end{tabular}


[My] long-term career goals have changed; so now I'm also interested in scientific writing/scientific communication roles. Things like policy/scientific advisory boards for broader impact also appeal to me. Especially when it comes to communicating science to politicians [scientific writing] can have a big impact on policy and can help drive effective policy making.

We found that participants were able to use their internship experiences to help them broaden their perspectives on possible career tracks. They took on new career opportunities that they had not considered before and, based on their internships, identified potential areas of career exploration in the future. In addition, participants were also able to use their internships as ways to correct their courses with respect to their long-term career plans. That is, while a career path may have been appealing before the internship, after a realistic job preview at an internship site, they learned that the job fit was not all that they had hoped for and that they must therefore continue their search elsewhere.

Regardless of whether the internships opened or closed doors, the internship experience overall was for many a confidence booster. As noted by one participant, "It has been reassuring that not enjoying the academic world is not a bad thing and you are not the one weird person who does not want to be a PI someday." Another intern stated that s/he has "gotten more confident in reaching out to professors for advice-based on experience from internship ... so new connects are not as intimidating anymore." In one case, the internship experience led to a desire for an accelerated degree completion, "Definitely want to graduate a lot faster now! There is no more waiting to figure out what needs to be done next."

\section{DISCUSSION}

Internships are widely regarded as a valuable complement to undergraduate training and readiness for the workforce across multiple disciplines (Daniel and Daniel, 2013; Massi et al., 2013; Rigsby et al., 2013). In 2011, 67\% of undergraduate students who participated in internship programs were eventually placed as full-time hires nationally (Massi et al., 2013). However, with the exception of the Schnoes et al. (2018) study, we were unable to determine whether internships were considered just as valuable for biomedical doctoral students and postdocs, and if so, what benefits did they accrue. In line with prior research on the efficacy of undergraduate internships (Stack and Fede, 2017), overall, we found that the internships for biomed doctoral students and postdocs were also perceived as effective career exploration and self-development vehicles. We present three key reasons that underlie this finding.

First, BEST candidates had the opportunity to explore a wide range of career tracks ranging from technology, intellectual property and patent law, research and innovation incubators, and scientific writing to technology transfer. Thus, the internships were vehicles for career exploration that pushed candidates out of their comfort zones of academic and lab work. Before their internships, candidates tended to describe their academic lives as akin to "a research bubble," "the narrow box," "the tunnel vision," and "my research cage" and stated that internships exposed them to career options outside academia. These phrases vividly surfaced a pattern whereby doctoral stu- dents and postdocs described confronting a restricted range of experiences in their research labs to the point of feeling boxed in and suffocated. In thinking about fellow lab members, one participant reflected, "I wish I could change their thinking somehow and make them realize that there is [sic] more options to explore." The internships provided outlets to break out of these confines and explore career tracks, work roles, and employment contexts that may not be traditionally considered to be viable career paths. Pursuing these new opportunities was described as a challenging experience and one that spurred individuals' professional and personal growth. Prior research shows that such career exploration attempts serve to broaden one's vocational self-concept (Drewery et al., 2016) and can nudge people into viewing the world through newly acquired lenses and mental models. For example, one participant noted that "one of the greatest [self-insights is to] step outside your bubble of academics - we are so focused on the science that we do not know much else outside." Another participant stressed that the "difference is day and night- - II had no idea about other possibilities. All I knew was the lab-now that has changed." Participants described how the internship experience opened up new career vistas for them that had not been on their radar before.

Furthermore, as part of career exploration, people gain some sense of the value-alignment between themselves and their jobs and/or vocations by assessing their perceived fit with a work domain (Kristof-Brown et al., 2005). Across the board, we saw evidence that participants made serious attempts to explore their fit vis-à-vis their jobs at the internship sites. For example, one participant noted,

[This internship] allowed me to close the right doors. If I hadn't done this, I would be wondering what the applied work would look like. The second internship solidified exactly what I want to do! The workshop to me went by so quickly-I'm really passionate about it, and this is something I would never have been able to experience had it not been for this opportunity. Now I am 100\% [sure I] want to be a data scientist. I don't know any life science researcher who is not a postdoc right now, so the data scientist world is a great world for me. I am grateful how the internships helped me [sic] solidify this for me! I am really confident in my ability to do this, and I wouldn't have this confidence had it not been for these experiences. I'm glad I got to see patent law in action and was therefore able to cancel it out [as a viable career track].

This sentiment was demonstrated over and over again in descriptions of internships as having opened doors, closed doors, and/or kept doors ajar to possible career tracks. Others described learning the norms and values of different industry settings and used these opportunities to assess how they might fit with different career tracks. For example, one participant noted that "industry values are different from academia. Industry does not care about being interested in just one question for the sake of [the] question alone. So, you have to reprogram your thinking."

Second, study participants described having learned both hard and soft skills at their internship sites, and in so doing described gaining marketable skills. They touted these KSAs as "CV builders" that they predicted would help differentiate them from other equally qualified candidates in the job market. Given 
the descriptions of the research labs as confined settings, it is no surprise that STEM doctoral students and postdocs are often unprepared to be effective in more team-based, fast-paced industry environments. A constant refrain from employers is that, while individuals possess the needed KSAs to do the industry jobs, they often struggle and demonstrate subpar soft skills (Fuhrmann et al., 2011), are ill-equipped to understand the business constraints and/or bottom lines, and find it difficult to work in tandem with diverse organizational stakeholders (Denecke et al., 2017; Petrie et al., 2017). Based on our data, it is evident how even short (40-80 hour) internship experiences led participants to feel that they had gained valuable soft skills and were empowered to take on industry settings. Thus, we view internships as a low-cost vehicle for facilitating students' readiness for jobs in industry.

Third, BEST candidates shared how the internships helped increase their confidence and self-efficacy. This finding is consistent with results reported by Schnoes et al. (2018), who found that internship programs provided students with the necessary confidence to take charge of their careers. There are several reasons for why most of our participants indicated feeling more confident about the job market. First, the candidates perceived the marketable KSAs that they learned as unique selling points in differentiating them from other STEM trainees whose work experiences were limited to traditional lab research. Second, they felt that they could apply these experiences to a different employment setting if necessary, based on how they had been able to effectively translate their 1 ) academic learning to the industry work experiences and 2) industry work experiences back to the lab setting. This was interpreted as an indicator for their own readiness to take on their aspirational career paths, and this is one reason why the internships were seen as such a life-altering experience by some. They may have walked into these experiences doubting their own capabilities, but most participants left with a sense of confidence in their own KSAs, their motivation, and their ability to thrive in different contexts. A third factor that has been related to enhancing individuals' self-efficacy is the power of effective mentoring (Kram, 1985; Koberg et al., 1998; Feldman et al., 2010). BEST candidates described receiving mentoring from both their faculty mentors and industry mentors. This powerful combination of feedback wherein the industry mentors echoed either candidates' own intuitions about viable career tracks and/or their academic mentors' assessment of their potential was described as an incredibly validating experience. For example, one participant noted how s/he has "increased confidence in [my] own abilities-validation at work."

\section{Practical Implications}

The data presented here paint a compelling portrait of how the internships were leveraged as tools to facilitate effective career decision making. Specifically, by harnessing the power of mentoring and networking experiences, learning new KSAs, and engaging in career exploration attempts to assess job/vocational fit, individuals were able to both exploit new career opportunities and explore beyond the traditional route to academia. Furthermore, graduate students and postdocs who choose to stay in academia might themselves feel better prepared to mentor future graduate students, having seen firsthand the value of such career exploration activities. Given these benefits, and the relatively low cost to taking on an internship (i.e., no reported delays in time to graduate, ability to conduct lab research and produce deliverables while concurrently engaging in career exploration), internships can be viewed as efficacious and adaptable interventions.

One way to address the challenges facing the biomedical and STEM doctoral and postdoc talent described earlier in the paper is to create institutional systems that can facilitate active ties with organizations. To do so, faculty, graduate programs, career centers, and university leadership will have to work synergistically. That is, at each level, resources need to be mobilized to foster alignment on strategic engagement with organizations. There is also a need to educate doctoral students and postdocs on the need to be more proactive with their career strategies, so they can engage in intentional and self-directed career exploration.

\section{Limitations and Directions for Future Research}

Our conclusions need to be interpreted in the light of three key limitations. First, these data were captured from biomedical graduate students and postdocs, so the findings can only be generalized to this group. Biomedical and STEM fields are characterized by unique challenges that may not necessarily apply to other educational settings. This is not to say that the internships could not be effective tools for gaining breadth of perspective and career exploration in other fields, but there will likely be qualitative differences in how the students approach, and benefit from, their internships. Given the limited empirical research on the utility of internships at graduate level (with the exception of the Schnoes et al., 2018, study), this area is ripe for future investigation including how the experiences affected one's career choice.

Second, our sample was recruited as part of an ongoing intervention on broadening careers. The participants were all part of the BEST cohort and had willingly joined the program that required internships as a key experiential learning intervention. Research on efficacy of mandatory versus voluntary internships is mixed in that mandatory internships-that is, required in order to earn their degree-at the undergraduate level did not yield participants a smooth transition into a job upon graduation or higher wages (Klein and Weiss, 2011). However, other studies have found positive effects of mandatory internships in lowering unemployment rates (Silva et al., 2018). It might be the case that doctoral students and postdocs, based on their maturity and life stage, perhaps are more likely to showcase motivated engagement with internships regardless of whether these are packaged as volitional or mandatory interventions. However, this is a speculative claim at best and should be empirically investigated.

It is also likely that our participants' proactive dispositions attracted them to participating in the BEST program in the first place. To contextualize this discussion, we use the concept of career adaptability as a case in point. Career adaptability describes how individuals may differ with respect to their "readiness to cope with the predictable tasks of preparing for and participating in the work role and with the unpredictable adjustments prompted by changes in work and working conditions" (Savickas, 1997, p. 254). The dimensions of career concern (i.e., awareness of and concern with future career trajectory), career control (i.e., extent of self-regulatory effort expended in seeking 
developmental experiences), career curiosity (i.e., willingness to engage in exploration efforts), and career confidence (i.e., self-efficacy with respect to persisting through novel and challenging landscapes) underlie career adaptability. Might it be the case that those with higher degree of career concern, career control, and career curiosity were attracted to join BEST, and also were more willing to stay the course in the pursuit of finding themselves a good fit for future employment? On the flip side of this, what might be barriers that are likely to hold students back from engaging in programs like BEST? These factors merit future research attention. In addition, more work is needed to unpack the complex and multidimensional construct of metacognitive skill development as a function of internship experiences.

Third, we assessed the individuals in our study at only one time point after their internship. This decision was necessitated because interviews are a highly time-intensive and resource-intensive research methodology. Participants noted that their internships were influential in how they saw their vocational identities and, in many cases, also impacted their choice of long-term career tracks. However, it is difficult to ascertain how lasting this influence will be. Research on professional identities suggests that certain experiences provide triggers that, if reflected upon deeply, can unfold stories and narratives about the self and create and/or change vocational identities in the process (Meijers and Lengelle, 2012). If the internships were as life-changing for some as the BEST candidates described, then our initial hunch is that the experience will persist in coloring and adding texture to how they view their careers.

\section{CONCLUSION}

Graduate school and postgraduate positions often make for environments that are marked by impending transitions into professional roles that are increasingly difficult to navigate, if, that is, an individual is indeed fortunate to find the right path forward from a wide array of viable career options. We found that graduate students and postdocs saw internships as instrumental in building their career management skills, obtaining mentoring and networking opportunities, and showcasing their ability to adapt their KSAs to industry work settings. Together, these different forces came together and helped doctoral students and postdocs gain confidence in action. In sum, internships were seen as life-changing events by many who described how their perspectives on viable career tracks were broadened.

\section{ACKNOWLEDGMENTS}

Research reported in this study was supported by the Office of the Director of the NIH under award number DP7OD020320. The content is solely the responsibility of the authors and does not necessarily represent the official views of the NIH.

\section{REFERENCES}

Alberts, B., Kirschner, M. W., Tilghman, S., \& Varmus, H. (2014). Rescuing US biomedical research from its systemic flaws. Proceedings of the National Academy of Sciences, 111(6), 5773-5777.

Arthur, M. B., \& Rousseau, D. M. (1996). The boundaryless career as a new employment principle. In Arthur, M. G., \& Rousseau, D. M. (Eds.), The boundaryless career (pp. 3-20). New York: Oxford University Press,

Austin, A. E. (2010). Reform efforts in STEM doctoral education: Strengthening preparation for scholarly careers. In Smart, J. C. (Ed.) Higher education: Handbook of theory and research. New York: Springer.
Austin, A. E., \& Wulff, D. H. (2004). The challenge to prepare the next generation of faculty. In Wulff, D. H., \& Austin, A. E. (Eds.), Paths to the professoriate: Strategies for enriching the preparation of future faculty ( $\mathrm{pp}$ 46-73). San Francisco: Jossey-Bass.

Baldwin, T. T., \& Ford, J. K. (1988). Transfer of training: A review and directions for future research. Personnel Psychology, 41(1), 63-105

Binder, J. F., Baguley, T., Crook, C., \& Miller, F. (2015). The academic value of internships: Benefits across disciplines and student backgrounds. Contemporary Educational Psychology, 41, 73-82.

Blustein, D. L. (1997). A context-rich perspective of career exploration across life roles. Career Development Quarterly, 45, 260-274.

Bridgstock, R. (2009). The graduate attributes we've overlooked: Enhancing graduate employability through career management skills. Higher Education Research \& Development, 28(1), 31-44.

Bright, J. E. H., \& Pryor, R. G. L. (2005). The chaos theory of careers: A user's guide. Career Development Quarterly, 53, 291-304.

Briscoe, J. P., Hall, D. T., \& DeMuth, R. L. F. (2006). Protean and boundaryless careers: An empirical exploration. Journal of Vocational Behavior, 69(1), 30-47.

Carnevale, A. P., Smith, N., \& Melton, M. (2011). STEM: Science technology engineering mathematics. Washington, DC: Georgetown University Center on Education and the Workforce.

Carney, J., Chawla, D., Wiley, A., \& Young, D. (2006). Evaluation of the initial impacts of the National Science Foundation's Integrative Graduate Education and Research Traineeship Program. Arlington, VA: National Science Foundation, Division of Research, Evaluation, and Communication and Abt Associates.

Council of Graduate Schools and Educational Testing Service. (2012). Pathways through graduate school and into careers: Report from the Commission on Pathways through Graduate School and into Careers. Princeton, NJ: Educational Testing Service.

Daniel, R., \& Daniel, L. (2013). Enhancing the transition from study to work: Reflections on the value and impact of internships in the creative and performing arts. Arts and Humanities in Higher Education, 12(2-3), 138-153.

Denecke, D., Feaster, K., \& Stone, K. (2017). Professional development: Shaping effective programs for STEM graduate students. Washington, DC: Council of Graduate Schools. Retrieved April 28, 2017, from http:// cgsnet.org/ck nder/user les/les/CGS_ProfDev_STEMGrads16_web.pdf

Drewery, D., Nevison, C., \& Pretti, T. J. (2016). The influence of cooperative education and reflection upon previous work experiences on university graduates' vocational self-concept. Education + Training, 58(2), 179-192.

Feldman, M. D., Arean, P. A., Marshall, S. J., Lovett, M., \& O'Sullivan, P. (2010). Does mentoring matter: Results from a survey of faculty mentees at a large health sciences university. Medical Education Online, 15(1), 5063.

Ford, J. K., Baldwin, T. T., \& Prasad, J. (2018). Transfer of training: The known and the unknown. Annual Review of Organizational Psychology and Organizational Behavior, 5, 201-225.

Fuhrmann, C. N., Halme, D. G., O'Sullivan, P. S., \& Lindstaedt, B. (2011). Improving graduate education to support a branching career pipeline: Recommendations based on a survey of doctoral students in the basic biomedical sciences. CBE-Life Sciences Education, 10(3), 239-249.

Golde, C. M. (2005). The role of the department and discipline in doctoral student attrition: Lessons from four departments. Journal of Higher Education, 76(6), 669-700.

Guest, G., Bunce, A., \& Johnson, L. (2006). How many interviews are enough? An experiment with data saturation and variability. Field Methods, 18(1) 59-82.

Gushue, G. V., Clarke, C. P., Pantzer, K. M., \& Scanlan, K. R. (2006). Self-efficacy, perceptions of barriers, vocational identity, and the career exploration behavior of Latino/a high school students. Career Development Quarterly, 54(4), 307-317.

Hancock, D. R., \& Algozzine, B. (2016). Doing case study research: A practical guide for beginning researchers. New York: Teachers College Press.

Hill, C. E., Thompson, B. J., \& Williams, E. N. (1997). A guide to conducting consensual qualitative research. Counseling Psychologist, 25, 517-572.

Klein, M., \& Weiss, F. (2011). Is forcing them worth the effort? Benefits of mandatory internships for graduates from diverse family backgrounds at labour market entry. Studies in Higher Education, 36(8), 969-987. 
Koberg, C. S., Boss, W., \& Goodman, E. (1998). Factors and outcomes associated with mentoring among health-care professionals. Journal of Vocational Behavior, 53, 58-72.

Kram, K. E. (1985). Mentoring at work: Developmental relationships in organizational life. Glenview, IL: Scott Foresman.

Kristof-Brown, A. L., Zimmerman, R. D., \& Johnson, E. C. (2005). Consequences of individuals' fit at work: A meta-analysis of person-job, person-organization, person-group, and person-supervisor fit. Personnel Psychology, 58(2), 281-342.

Larson, R. C., Ghaffarzadegan, N., \& Xue, Y. (2014). Too many PhD graduates or too few academic job openings: The basic reproductive number RO in academia. Systems Research and Behavioral Science 31(6), 745-750.

Leong, F. T., \& Morris, J. (1989). Assessing the construct validity of Holland, Daiger, and Power's measure of vocational identity. Measurement and Evaluation in Counseling and Development, 22(3), 117-125.

Mason, M. (2010). Sample size and saturation in PhD studies using qualitative interviews. In Forum Qualitative Sozialforschung/Forum: Qualitative Social Research, 11(3), 1-19.

Massi, L., Georgiopoulos, M., Youn, C. Y., Ford, C. M., \& Lancey, P. (2013) Internships and undergraduate research: Impact, support, and institutionalization of an NSF S-STEM program through partnerships with industry and funding from federal and local workforce agencies. Age, 23, 1.

Meijers, F., \& Lengelle, R. (2012). Narratives at work: The development of career identity. British Journal of Guidance \& Counselling, 40(2), 157176.

Mirvis, P. H., \& Hall, D. T. (1994). Psychological success and the boundaryless career. Journal of Organizational Behavior, 15(4), 365-380.

Mitchell, K. E., Al Levin, S., \& Krumboltz, J. D. (1999). Planned happenstance: Constructing unexpected career opportunities. Journal of Counseling \& Development, 77(2), 115-124.

Monastersky, R. (2007). The real science crisis: Bleak prospects for young researchers. Chronicle of Higher Education, 54(4), A1.

Myers, F. J., Mathur, A., Fuhrmann, C. N., O'Brien, T. C., Wefes, I., Labosky, P. A., ... Friedlander, M. J. (2015). The origin and implementation of the Broadening Experiences in Scientific Training programs: An NIH common fund initiative. FASEB Journal, 30(2), 507-514.

Nyquist, J. D., Austin, A. E., Sprague, J., \& Wulff, D. H. (2001). The development of graduate students as teaching scholars: A four-year longitudinal study. Seattle: University of Washington, Center for Instructional Development and Research.

O'Brien, B. C., Harris, I. B., Beckman, T. J., Reed, D. A., \& Cook, D. A. (2014). Standards for reporting qualitative research: A synthesis of recommendations. Academic Medicine, 89(9), 1245-1251.
Passow, H. J. (2007). What competencies should engineering programs emphasize? A meta-analysis of practitioners' opinions informs curricular design. In Proceedings of the 3rd International CDIO Conference (pp. 1-36). Cambridge, MA

Petrie, K. A., Carnahan, R. H., Brown, A. M., \& Gould, K. L. (2017). Providing experiential business and management training for biomedical research trainees. CBE-Life Sciences Education, 16(3), ar51.

Rigsby, J. T., Addy, N., Herring, C., \& Polledo, D. (2013). An examination of internships and job opportunities. Journal of Applied Business Research, 29(4), 1131-1143.

Ritchie, J., Lewis, J., Nicholls, C. M., \& Ormston, R. (Eds.). (2013). Qualitative research practice: A guide for social science students and researchers. Thousand Oaks, CA: Sage.

Ritchie, J., Spencer, L., \& O'Connor, W. (2003). Carrying out qualitative analysis. In Ritchie, J., Lewis, J., Nicholls, C. M., \& Ormston, R. (Eds.), Qualitative research practice: A guide for social science students and researchers (pp. 219-262). London: Sage.

Savickas, M. L. (1997). Adaptability: An integrative construct for life-span, lifespace theory. Career Development Quarterly, 45, 247-259.

Schnoes, A. M. M., Caliendo, A., Morand, J., Dillinger, T., Naffziger-Hirsh, M., Moses, B., \& O'Brien T. C. (2018). Internship experiences contribute to confident career decision making for doctoral students in the life sciences. CBE-Life Sciences Education, 17(1), ar16.

Silva, P., Lopes, B., Costa, M., Melo, A. I., Dias, G. P., Brito, E., \& Seabra, D. (2018). The million-dollar question: Can internships boost employment? Studies in Higher Education, 43(1), 2-21.

Stack K., \& Fede J. (2017). Internships as a pedagogical approach to soft-skill development. Retrieved August 14, 2018, from www.naceweb.org/ career-readiness/internships/internships-as-a-pedagogical-approach -to-soft-skill-development

Stumpf, S. A., Colarelli, S. M., \& Hartman, K. (1983). Development of the career exploration survey (CES). Journal of Vocational Behavior, 22(2), 191-226.

Sullivan, S. E. (1999). The changing nature of careers: A review and research agenda. Journal of Management, 25(3), 457-484.

Sullivan, S. E., \& Baruch, Y. (2009). Advances in career theory and research: A critical review and agenda for future exploration. Journal of Management, 35(6), 1542-1571.

Thanh, N. C., \& Thanh, T. T. (2015). The interconnection between interpretivist paradigm and qualitative methods in Education. American Journal of Educational Science, 1(2), 24-27.

Xue, Y., \& Larson, R. C. (2015, May). STEM crisis or STEM surplus? Yes and yes. Monthly Labor Review. doi: 10.21916/mlr.2015.14

Zikic, J., \& Hall, D. T. (2009). Toward a more complex view of career exploration. Career Development Quarterly, 58, 181-191. 